\title{
Capital Ownership And Its Impact On International Trade And Economic Growth: The Tunisian Experience
}

Khalifa H. Ghali, (Email: kghali@cba.edu.kw), Kuwait University, The State of Kuwait Hedi Trabelsi, Faculte des Sciences Economiques et de Gestion, Tunis - Tunisia

\begin{abstract}
Despite the widespread belief that a privatized economy performs better than a centrally planned one, there is no empirical evidence on whether changing the structure of capital ownership affects trade and growth in developing countries. This paper addresses this issue by analyzing and comparing the distinctive effects of privately and publicly owned capital on international trade and economic growth. Based on a modified version of the neo-classical one-sector aggregate production technology, we investigate the intertemporal interactions among the growth rate of real output, private capital, public capital, international trade and labor. The results of applying our methodology to data from Tunisia suggest that private capital performs better than public capital in promoting economic growth and international trade. Despite the widespread belief that a privatized economy performs better than a centrally planned one, there is no empirical evidence on whether changing the structure of capital ownership affects trade and growth in developing countries. This paper addresses this issue by analyzing and comparing the distinctive effects of privately and publicly owned capital on international trade and economic growth. Based on a modified version of the neo-classical one-sector aggregate production technology, we investigate the intertemporal interactions among the growth rate of real output, private capital, public capital, international trade and labor. The results of applying our methodology to data from Tunisia suggest that private capital performs better than public capital in promoting economic growth and international trade.
\end{abstract}

\section{INTRODUCTION}

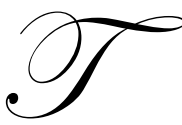

he transition from centrally planned into decentralized market economies is one of the most important economic issues of our time. The failure of the socialist system to achieve an efficient allocation of resources led to a strong belief that only an alteration of the economic structure could improve the well being of a society. The most important of these alterations is the privatization of state-owned enterprises, which in the presence of working markets should improve the allocation efficiency of resources and the living standards. This issue is of particular interest to developing countries. In the aftermath of the debt crisis, and upon recommendations by international financial institutions, many developing countries are changing their overall development strategies to rely more heavily on market forces. Consequently, these countries are witnessing a large process of deregulation of product and factor markets and the privatization of public enterprises ${ }^{1}$.

However, while most economists believe that a privatized economy performs better than a centrally planned one, the theoretical justification why this should be is still an open question. This issue dates back to the famous Hayek-Lerner-Lange debate of the 1940's. The latter two authors argue that a planned economy could at least result in as good an outcome as a market system, because it could always mimic it. However, Hayek was convinced that the beneficial thrives of the Schumpeterian entrepreneurship could only be exploited in a system of decentralized individual decision making. In addition, an important reason to privatize is that state owned firms are 'politicized', and the main objective of politicized firms is to satisfy interests of bureaucrats and politicians. To prevent social

\footnotetext{
${ }^{1}$ See Bennedsen (1998), Glaeser, Edward, and Sleifer (1998).
} 
unrest and maintain their power, those groups favor excess employment, ineffective locations or under pricing of output. However, in privately owned firms profit is the main concern of the holders of property rights. Hence, one important target of privatization is to reduce the influence of the political system on the allocation process ${ }^{2}$.

Recently, Shleifer (1998) notices that postwar economists generally failed to anticipate the failure of state ownership and argued that the widespread belief of the 1940's in favor of government production is no longer convincing. He adds that past empirical observations on some apparent success of government control during the Second World War and the failures of deregulation and competition during the Great Depression were misleading. In addition, there was a misunderstanding of the consequences of political control of firms and no importance was given to innovation in market economies. Recently, however, the collapse of the communist economies and the large improvements in the quality of regulation and contracting made the benefits of reducing the role of the government as a producer more convincing.

The empirical literature on the issue has taken the form of an extensive analysis of the effects of government spending on aggregate outcomes such as real output or per capita real GDP. In particular, the resurgence of interest in endogenous growth theory and the ongoing process of liberalization and privatization in many developing countries initiated a new body of empirical research aiming at determining the relationship between private and public investment and its potential impact on long-run economic growth. Empirical investigations of the issue were made by Feder (1983), Landau (1983), Kormendi and Meguire (1985, 1990), Ram (1986), Ramirez (1986b, 1991, 1994), Easterly (1992), Barro (1981, 1990, 1991), Barro and Sala-i-Martin (1992), Hsieh and Lai (1994), Ghali (1999), Nourzad (2000), among others.

However, this literature did not provide a consensus judgment concerning the relationship between private investment, public investment, and economic growth. Moreover, while the question is so important, theoretical positions are quite diverse. Some points of view suggest that public investment undertaken by heavily subsidized and inefficient state-owned enterprises has often reduced the possibilities for private investment and long-run economic growth. Moreover, the repression of the private financial system has crowded-out the private sector from profitable investment opportunities. At the other extreme there are points of view which suggest that in countries characterized by the existence of monopolies, the lack of fully developed markets of capital, insurance and information, public sector investment can make product and factor markets work more efficiently and, hence, generate a substantial spillover effect for the private sector.

In light of the mixed evidence and views, the existing literature cannot provide the basis on which a particular country can decide on the appropriate mix of capital ownership, nor does it allow gauging whether an expanding private (public) sector investment would accelerate or depress its growth process. Moreover, since economic policies tend to be country specific and their success depends largely on the institutions implementing them, a policy recommendation cannot safely be made by generalizing the experiences from other countries.

Therefore, the aim of this paper is to empirically analyze the distinctive effects of privately and publicly owned capital on output growth and international trade in the case of Tunisia. Recently, this country started an ambitious structural adjustment program where privatization is believed to be the main driver of success for promoting international trade and long-run economic growth. However, in the absence of empirical evidence, some opponents to privatization are raising doubts about the role of the private sector and its ability to take the lead and compete successfully in the global economy. In recent years, Tunisia's economic development model has proven to be the most successful among developing countries implementing structural adjustment programs, with a growth rate reaching 5.5\% in 2001. Consequently, empirical evidence on the issue would shed light on the relative merits and contributions of private and public investments to the growth process and, would provide policy makers with a solid basis on which the allocation efficiency of the country's resources can be further enhanced.

Using a modified version of the neo-classical one-sector aggregate production technology, these effects are herein investigated in a five-variable system consisting of real output, private investment, public investment,

\footnotetext{
${ }^{2}$ See Boycko et al. (1995).
} 
international trade and labor. The short- and long-run dynamic interactions between these variables are empirically investigated using a vector error-correction (VEC) model which we use to test for cointegration and Granger noncausality. Within this framework, we search for structural beaks due to shifts in Tunisia's economic policy and identify the causal links among the variables. In particular, we use variance decompositions and estimate the separate effects of private and public capital on international trade and economic growth. The main findings that are useful for the conduct of economic policy in this country are: (i) there is a unidirectional causal relationship running from private investment to public investment. This means that public investment is following rather than anticipating changes in private investment. Hence, an increase in public investment does not constitute an effective policy for promoting private investment. However, a growing private sector will in due time induce the public sector to provide essential investments in social and economic infrastructure; and (ii) while both sorts of investment lead to economic growth, an increase in the share of private investment in GDP generates a permanent effect on economic growth and international trade which is much higher than a similar increase in the share of public investment in GDP. It follows that an effective economic policy targeting growth and trade promotion should encourage private ownership of capital, while the government should assist this process by providing a favorable environment that enhances the competitiveness of the economy.

The remaining of the paper is organized as follows. Section II presents the theoretical framework. Section III describes the econometric methodology. Section IV contains the main results and section V concludes.

\section{THE THEORETICAL FRAMEWORK}

To analyze the separate effects of private investment and public investment activities on international trade and economic growth, we propose a framework based on the conventional neo-classical one-sector aggregate production technology in which public and private capital stocks are treated as separate inputs. That is

$Y_{t}=f\left(L_{t}, K_{t p}, K_{t g}, X_{t}\right)$

where $\mathrm{Y}=$ aggregate output or real GDP; $\mathrm{L}=$ labour force; $\mathrm{K}_{\mathrm{p}}=$ private capital stock; $\mathrm{K}_{\mathrm{g}}=$ public capital stock; $\mathrm{X}=$ real exports, and the subscript $t$ denotes the time period. The inclusion of real exports as an argument in the production function can be justified with reference to the several recent studies (Feder, 1983; Edwards, 1989; Dollar, 1992; Grossman and Helpman, 1990; Levine and Renelt, 1992; Ghali, 1999, among others) which have empirically detected positive and significant effects of export expansion on economic growth. By taking the differential of equation (1) we obtain

$d Y_{t}=Y_{L} d L_{t}+Y_{K p} d K_{p t}+Y_{K g} d K_{g t}+Y_{X} d X_{t}$

where $Y_{i}$ is the partial derivative of $Y$ with respect to its $i$ th argument. On dividing equation (2) through by $Y_{t}$ and rearranging the resulting expression, we obtain the following growth equation.

$\dot{\mathrm{Y}}_{\mathrm{t}}=\dot{\mathrm{aL}}_{\mathrm{t}}+\dot{\mathrm{bK}}_{\mathrm{pt}}+\dot{\mathrm{c}}_{\mathrm{gt}}+\dot{\mathrm{d}}_{\mathrm{t}}$

where the dot on top of a variable signifies that the variable is now in a growth rate form. The constant parameters a, $\mathrm{b}, \mathrm{c}$, and d are the elasticities of output with respect to labor, private capital, public capital and exports, respectively. Since data is usually not available on both private and public capital stocks, these variables can be easily replaced by their respective shares in GDP as follows

$\dot{\mathrm{Y}}_{\mathrm{t}}=\dot{\mathrm{aL}}_{\mathrm{t}}+\alpha_{\mathrm{p}}\left(\mathrm{I}_{\mathrm{pt}} / \mathrm{Y}_{\mathrm{t}}\right)+\alpha_{\mathrm{g}}\left(\mathrm{I}_{\mathrm{gt}} / \mathrm{Y}_{\mathrm{t}}\right)+\dot{\mathrm{d}}_{\mathrm{t}}$

where $\alpha_{\mathrm{p}}$ is the marginal productivity of private capital and $\alpha_{\mathrm{g}}$ is the marginal productivity of public capital.

The model in (4) provides the theoretical underpinnings for investigating the separate effects of private and public investment on economic growth. It constitutes a significant improvement on the existing ones in which the 
relationship between private and public investment is investigated on an ad hoc basis but other growth determiningfactors such as labor and exports are excluded as regressors thereby making the estimates of equation (4) very susceptible to bias.

\section{ECONOMETRIC METHODOLOGY}

\section{Testing For Cointegration}

To model the relationship between real gross domestic product $(R G D P)$, the share of private investment in GDP $(P I)$, the share of public investment in GDP $(G I)$, exports $(X)$, and labor $(L)$, we consider that their short-run dynamics can be represented by a vector autoregression VAR specification as follows:

$X_{t}=c+\pi_{1} X_{t-1}+\ldots+\pi_{k} X_{t-k}+\Psi D_{t}+\varepsilon_{t}$

where $\mathrm{X}=(R G D P, P I, G I, X, L)^{\prime}, t$ is time, $\mathrm{c}$ is a $5 \mathrm{x} 1$ vector of constants or drift terms, $\pi_{\mathrm{i}}, \mathrm{i}=1 \ldots \mathrm{k}$, are $5 \times 5$ matrices of time-invariant coefficients, and $\varepsilon$ is a $5 \times 1$ vector of i.i.d errors with a positive covariance matrix. $\mathrm{D}$ is a matrix of deterministic components such as trend and dummies. The $\operatorname{VAR}(\mathrm{k})$ model defined in equation (5) is covariance stationary if all values of $Y$ satisfying:

$$
\left|\mathrm{I}-\pi_{1} \mathrm{Y}-\pi_{2} \mathrm{Y}^{2}-\ldots-\pi_{\mathrm{k}} \mathrm{Y}^{\mathrm{k}}\right|=0
$$

lie outside the unit circle.

If some or all the variables in $\mathrm{X}$ are $\mathrm{I}(1)$, then we can exploit the idea that there may exist co-movements of these variables and possibilities that they will trend together towards a long-run steady-state equilibrium (i.e cointegrated). Hence, their behavior can now be represented using a vector error-correction (VEC) model that incorporates the short-run as well as the long-run dynamics,

$\Delta X_{t}=\mathrm{c}+\sum_{i=1}^{p-1} \Gamma_{i} \Delta X_{t-p}+\Pi X_{t-p}+\Psi D_{\mathrm{t}}+\varepsilon_{\mathrm{t}}$

where $\Pi=-\left(\mathrm{I}-\Sigma_{\mathrm{i}} \pi_{\mathrm{i}}\right), \mathrm{i}=1, \ldots \mathrm{p}$, is the long-run parameter matrix, $\Gamma_{\mathrm{i}}=-\left(\pi_{\mathrm{i}+1}+\ldots+\pi_{\mathrm{i}}\right), \mathrm{i}=1, \ldots, \mathrm{p}-1$ are estimable parameters, $\Delta$ is a difference operator and $\varepsilon_{\mathrm{t}}$ is a vector of impulses which represent the unanticipated movements in $\mathrm{X}_{\mathrm{t}}$ with $\varepsilon_{\mathrm{t}} \sim \operatorname{niid}(0, \Sigma)$.

With $\mathrm{r}$ cointegrating vectors $(1 \leq \mathrm{r} \leq 4)$, $\Pi$ has rank $\mathrm{r}$ and can be decomposed as $\Pi=\alpha \beta^{\prime}$, with $\alpha$ and $\beta$ both $5 \mathrm{x}$ r matrices. $\beta$ is the matrix of cointegrating vectors and $\alpha$ are the adjustment coefficients which measure the strength of the cointegrating vectors in the VEC model.

The Johansen (1988) approach uses a maximum likelihood procedure to test the cointegrating rank $\mathrm{r}$ and estimate the parameters $\beta$ and $\alpha$. If the cointegration test reveals the existence of long-run relationships between the variables in $\mathrm{X}$, then several implications including "spurious" regression, Granger non-causality, and dynamic simulations can be established.

One advantage of the cointegration methodology is that it illustrates the conflict that exists between the equilibrium framework and the disequilibrium environment from which the data are collected. As illustrated by the VEC model in (7), this conflict can be easily resolved by extending the equilibrium framework into one that accounts for disequilibrium by including the equilibrium error measured by $\left(\beta^{\prime} \mathrm{X}_{\mathrm{t}-1}\right)$. Once the equilibrium conditions are imposed, the model is now describing how the system is adjusting towards its long-run equilibrium state. Since the variables are supposed to be cointegrated then, in the short-run, deviations from the long-run equilibrium will feed back on the changes in the dependent variables in order to force their movements towards the long-run equilibrium 
state. Thus, the adjustment coefficients $\alpha$ measure the proportion by which the long-run disequilibrium (or imbalance) in the dependent variables are corrected in each short-term period.

\section{Testing For Granger Non-Causality}

There are several procedures for testing Granger noncausality (GNC) using vector autoregressive models. These were developed and studied by Toda and Phillips (1993, 1994), Toda (1995), Dolado and Lutkepohl (1996), Zapata and Rambaldi (1997), and Yamada and Toda (1998). Recent surveys of these procedures are in Caporale and Pittis (1999). A comparison of the properties of these procedures based on simulation experiments can be found in Giles and Mirza (1999).

However, the choice between the alternative procedures depends on the pretesting for integration and cointegration among the variables. That is, depending on the degree of integration of the variables included in the system and depending on whether they are "sufficiently" cointegrated, there is a particular specification of VAR that adequately ensures appropriate behavior of the test statistic for testing the null of GNC. In particular, there are four different specifications. These are the VAR in levels (VARL) model, the augmented VARL model, the vector errorcorrection model (VECM), and the VAR in difference (VARD) model. In each one of these models, the statistic used to test for GNC is a Wald statistic ${ }^{3}$.

In general, if $\theta$ is an $m x 1$ vector of parameters and $\mathrm{R}$ is a nonstochastic qxm matrix of known parameters with rank q, then the Wald statistic to test $\mathrm{H}_{0}$ : $\mathrm{R} \theta=0$ is

$$
W=T \hat{\theta}^{\prime} R^{\prime}\left\{R \hat{V}(\hat{\theta}) R^{\prime}\right\}^{-1} R \hat{\theta}
$$

where $\hat{\theta}$ is a consistent estimator of $\theta, \hat{V}(\hat{\theta})$ is a consistent estimator of the asymptotic variance-covariance matrix of $\sqrt{T}(\hat{\theta}-\theta)$, and $T$ is the number of observations. Under appropriate conditions, $W$ is asymptotically distributed as a $\lambda^{2}(\mathrm{q})$ distribution under the null.

In the context of a VEC model, the null of GNC can be tested in three different ways using the Wald statistic in (8). First, zero restrictions can be imposed on the $\alpha$ vector to test for weak exogeneity of the variables. Toda and Phillips $(1993,1994)$ refer to these tests as long-run noncasality tests. Second, zero restrictions can be imposed on the coefficients of the $\Gamma$ matrix to test whether the lagged coefficients of a variable are zero. This test is referred to as a short-run noncausality test. Finally, zero restrictions can be imposed jointly on the coefficients in $\alpha$ and $\Gamma$ to test for both short-and long-run noncausality.

\section{EMPIRICAL RESULTS}

\section{Data And Variables Definition}

Data used in this study consist of annual series for Tunisia over the period $1960-2002$. The variables and their definitions where ln denotes the natural logarithm are as follows:

$R G D P: \ln ($ real $G D P)$,

$P I: \ln ($ the ratio of private investment to GDP),

GI: $\ln$ (the ratio of public investment to GDP),

$X: \ln ($ real exports),

$L: \ln ($ labor force).

\footnotetext{
${ }^{3}$ See Giles and Mirza (1999) for an extensive discussion of these models and a discussion of the comparative testing procedures.
} 
The source of all data series is the ministry of finance in Tunisia. GDP is the gross domestic product, $R G D P$ is GDP deflated by the GDP-deflator. Private investment is measured by the total private-business investment and public investment is measured by government capital expenditures. Exports refer to total exports. The labor force refers to the total labor force employed, including agricultural employment. The first difference of $R G D P$ is taken to be a proxy for economic growth.

\section{Test Results For Unit Roots}

In order to justify testing for cointegration, we herein investigate the time series properties of the data. Moreover, given that various policy changes may have taken place during the period of estimation, it is plausible to allow for the existence of structural breaks when testing for unit roots. In this respect, Perron (1989) demonstrated that the Dickey-Fuller test is biased against rejecting the null hypothesis of a unit root when the true data generating process is in fact trend stationary with a break in the intercept or the slope of the trend function. Consequently, Perron (1989) proposed to test the unit root null using a modified Dickey-Fuller test which specifies the alternative under the following three characterizations of the trend-break:

The Crash Model: This model allows for a change in the intercept under the null and alternative hypotheses. In addition, this change is assumed to occur gradually and in a way that depends on the correlation structure of the noise function. This model was termed the "innovational outlier model" in the terminology of Perron (1989) and will be denoted later by model IO1. The null hypothesis of a unit root is tested using the $t$-statistic for testing $\alpha=1$ in the following regression

$$
y_{t}=\mu+\theta D U_{t}+\beta t+\delta D\left(T_{b}\right)+\alpha y_{t-1}+\sum_{i=1}^{k} c_{i} \Delta y_{t-1}+e_{t}
$$

where $T_{b}$ is the time of the break, $D U_{t}=1\left(t>T_{b}\right)$ and $D\left(T_{b}\right)_{t}=1\left(t=T_{b}+1\right)$ with $1($.$) being the indicator function.$

The Mixed Model: This model allows for a break to occur simultaneously in both the intercept and the slope at time $T_{b}$. This model is also an innovational outlier model where the change occurs gradually in both the intercept and the slope. This model will be denoted by model IO2. In this model the unit root test is performed using the $t$-statistic for the null hypothesis that $\alpha=1$ in the following regression

$$
y_{t}=\mu+\theta D U_{t}+\beta t+\gamma D T_{t}+\delta D\left(T_{b}\right)+\alpha y_{t-1}+\sum_{i=1}^{k} c_{i} \Delta y_{t-i}+e_{t}
$$

where $D T_{t}=1\left(t>T_{b}\right) t$.

The Changing Growth Model: In this model only a change in the slope is allowed with both segments of the trend function are joined at the time of the break $T_{b}$. Moreover, the change here is supposed to occur rapidly and corresponds to the "additive outlier model" in the terminology of Perron (1989). This model will be denoted by model AO. To test the unit root hypothesis, Perron (1989) uses a two-step procedure. First, the series is detrended using the following regression where $\mathrm{DT}=1\left(t>T_{b}\right)\left(t-T_{b}\right)$

$$
y_{t}=\mu+\beta t+\gamma D T_{t} *+\tilde{y}_{t} .
$$

Then the test is performed using the t-statistic for $\alpha=1$ in the regression:

$$
\tilde{y}_{t}=\alpha \tilde{y}_{t-1}+\sum_{i=1}^{k} c_{i} \tilde{y}_{t-i}+e_{t}
$$


In order to device unit root tests that have power against the trend break stationary alternative, Perron (1989) first specifies the location of the break-date $T_{b}$. Then, given the break-date, he estimates a regression that nests the random walk null and the trend-break stationary alternative of choice. The assumption that the break date is known a priori was, however, criticized because the choice of $T_{b}$ is correlated with data, which makes Perron (1989) test reject the unit root null too often (see for example Christiano 1992; Banerjee, Lumsdaine and Stock 1992; Zivot and Andrews 1992, and Perron and Vogelsang 1992).

In order to avoid this bias, some studies have proposed extensions of Perron's (1989) unit root tests where the break-date is endogenously determined: Zivot and Andrews (1992), Banerjee et. al. (1992), Perron and Vogelsand (1992), Perron (1997), and Vogelsand and Perron (1998), among others. These studies have proposed to apply Perron's (1989) methodology for each possible break date in the sample, which yields a sequence of $t$-statistics. Then, using this sequence, a minimum $t$-statistic can be constructed that maximizes evidence against the null hypothesis. Therefore, the availability of the minimum $t$-statistics avoids the need for the a priori knowledge of the break-date.

Although the issue of break-date determination has been resolved, the issue that still remains is how to choose between the three alternatives of the unit root test. That is, how to characterize the form of the break. In this respect, Sen (2003) argues that the selection of the form of the break is also correlated with the data and, therefore, misspecification of the alternative may induce power distortions. He assessed the performance of the minimum $t$ statistics when the form of the break is misspecified. The simulation results of Sen (2003) indicate that the loss of power is minimized when the mixed model specification is used to characterize the form of the break. Therefore, he suggests that practitioners should use the form of the break specified under the mixed model IO2, which is the most general characterization under the alternative, unless prior information suggests using either the crash model IO1 or the changing growth model AO.

Table 1 below reports the results of testing for unit roots in the variables under the trend-break hypothesis. Since the form of the break is unknown, we followed the recommendation in Sen (2003) and used the mixed model IO2 in (10) as the alternative. The choice of the appropriate break date $\left(T_{b}\right)$ and order of the lag-truncation parameter $(k)$ are determined endogenously following Perron (1997), with $k$-max $=12$. In particular, the break-date $T_{b}$ is selected as the value which minimizes the $t$-statistic for testing $\alpha=1$. The truncation lag parameter $k$ is selected using a general-to-specific recursive procedure based on the $t$-statistic on the coefficient associated with the last lag in the estimated autoregression. That is, the procedure selects the value of $k$ such that the coefficient on the last lag in an autoregression is significant, up to a maximum order $k$-max.

Table 1: Test Results for Unit Roots

\begin{tabular}{|c|c|c|c|c|c|c|c|c|c|c|}
\hline Series & $\mathrm{k}$ & $\mathrm{T}_{\mathrm{b}}$ & $t_{\hat{\theta}}$ & $t_{\hat{\beta}}$ & $t_{\hat{\gamma}}$ & $t_{\hat{\delta}}$ & $\hat{\alpha}$ & $t_{\hat{\alpha}}$ & $10 \%$ & $5 \%$ \\
\hline RGDP & 9 & 1988 & 3.541 & 4.012 & 3.608 & 4.733 & 0.914 & -3.127 & -5.29 & -5.59 \\
\hline PI & 4 & 1988 & 2.303 & 3.725 & 3.290 & 3.661 & 0.956 & -2.690 & -5.29 & -5.59 \\
\hline GI & 2 & 1988 & -2.916 & -2.605 & 2.881 & 2.330 & 0.939 & -2.751 & -5.29 & -5.59 \\
\hline$X$ & 8 & 1988 & 3.466 & 3.541 & 3.601 & 3.255 & 0.971 & -3.382 & -5.29 & -5.59 \\
\hline $\mathrm{L}$ & 2 & 1988 & 2.673 & 4.311 & 5.164 & 2.013 & 0.912 & -3.016 & -5.29 & -5.59 \\
\hline
\end{tabular}

For each series, table 1 reports the truncation lag $k$, the estimated break date $\left(T_{b}\right)$, and the $t$-statistics of the parameters in equation (10). The last three columns report the unit root test statistics and critical values. The results of 
the table indicate that the unit root hypothesis cannot be rejected for all series. Additional unit root testing on the differenced series indicates that all variables are I(1) processes. Looking at the estimated break date $\left(T_{b}\right)$, we can see that a break in the trend functions of the variables has occurred in 1988. The most plausible explanation for a structural change occurring at this date is the change of the political regime in Tunisia in November 1987, which was coupled with the beginning of implementation of the IMF-sponsored structural adjustment programs. Prior to 1988, the economic situation in Tunisia was degrading. When the new government took control, significant restructuring and reforms were undertaken to re-orient the economy from a centrally planned one into an open, market-oriented one $^{4}$.

\section{Test Results For Cointegration}

Before testing for cointegration, we consider two main issues relevant to the Johansen testing procedure. First, in order for the model to capture the effects of structural change, we have included a shift dummy in the deterministic part of VAR, i.e. in D in (7). The dummy variable included is denoted by DUM and takes the value 1 after 1988 and 0 otherwise.

Second, it is important to carefully determine the lag length in VAR in order to avoid spurious causality (or absence of causality). In this respect, the number of lags was determined using both the Akaike information criterion (AIC) and the Schwartz criterion (SC) and was set equal to four. According to the simulation results of Giles and Mirza (1999), these two criteria were found to be the preferred lag-selection methods in terms of optimizing the properties of the Granger noncausality statistics when using the Johansen method. Using $\mathrm{k}=4$, we also tested for normality and for serial correlation in the residuals of VAR. The results of these tests, which are not reported here, indicate that this lag-length left the residuals approximately independently identically normally distributed.

Table 2: Test Results For Cointegration

\begin{tabular}{|c|c|c|c|c|c|c|c|c|}
\hline \multicolumn{4}{|c|}{ Trace } & \multicolumn{4}{|c|}{$\lambda_{\max }$} & \multirow[b]{2}{*}{$\lambda$} \\
\hline $\mathrm{H}_{0}$ & $\mathrm{H}_{1}$ & Stat. & $90 \%$ & $\mathrm{H}_{0}$ & $\mathrm{H}_{1}$ & Stat. & $90 \%$ & \\
\hline$r=0$ & $r \geq 1$ & 88.10 & 71.66 & $r=0$ & $r=1$ & 38.65 & 21.74 & 0.650 \\
\hline$r \leq 1$ & $r \geq 2$ & 41.35 & 49.92 & $r \leq 1$ & $r=2$ & 16.53 & 18.03 & 0.453 \\
\hline$r \leq 2$ & $r \geq 3$ & 25.40 & 31.88 & $r \leq 2$ & $r=3$ & 10.02 & 14.09 & 0.231 \\
\hline$r \leq 3$ & $r \geq 4$ & 12.91 & 17.79 & $r \leq 3$ & $r=4$ & 6.35 & 10.29 & 0.102 \\
\hline$r \leq 4$ & $r \geq 5$ & 4.86 & 7.50 & $r \leq 4$ & $r=5$ & 4.96 & 7.50 & 0.065 \\
\hline
\end{tabular}

The results of testing for the number of cointegrating vectors are reported in table 2 , which presents the maximum eigenvalue $\left(\lambda_{\max }\right)$ and the trace statistics, the 10 percent critical values as well as the corresponding $\lambda$ values. This test is performed using an unrestricted formulation of the VAR model which assumes the existence of a deterministic linear time trend in the data with an intercept in the cointegrating vector.

The results in table 2 indicate the existence of a unique cointegrating vector driving the series. However, this result was obtained under the assumption of the existence of a deterministic linear time trend in the data. Therefore, we test this assumption together with the rank order using the procedure suggested by Johansen (1992b, 1994), which jointly tests the cointegrating rank $r$ and the existence of a deterministic time trend in the data. This procedure is sequential and uses a $\chi^{2}$-test based on the so-called Pantula principle (Pantula, 1989). The procedure of this test is as follows. Let $\mathrm{M}_{\mathrm{ij}}$ denote the combination of rank and deterministic component where $\mathrm{i}$ is the rank $(\mathrm{i}=0,1, \ldots, 4)$ and $\mathrm{j}$ is the model, $\mathrm{j}=0$ is the model with no time trend in the data and $\mathrm{j}=1$ is the model with a deterministic time trend in the data. We start from the most restricted model $\mathrm{M}_{00}$ and compare the trace test statistic to the corresponding critical value. If the model is rejected we keep the rank assumption and change the model of the deterministic trend to the

\footnotetext{
${ }^{4}$ For an in-depth survey of Tunisia's structural reforms and economic performance, see IMF country reports (1999-2002). Recent economic
} performance of Tunisia can also be found in Saddem (2001). 
next one. So we continue to model $\mathrm{M}_{01}$. If this model is also rejected we change the rank to $\mathrm{i}=1$ and go through the same procedure for $\mathrm{j}=0$ and $\mathrm{j}=1$. We keep changing $\mathrm{i}$ and $\mathrm{j}$ until the first time the joint hypothesis is accepted. The results of this test are reported in table 3 where we can see that model $\mathbf{M}_{11}$ is the one consistent with the data. Therefore, we continue to use an unrestricted specification of VAR with linear deterministic trends in the data and one cointegrating vector.

Table 3: Joint Determination of the Rank and Deterministic Components

\begin{tabular}{lccc}
\hline Specification & Trace & $90 \%$ & Decision \\
\hline $\mathrm{M}_{00}$ & 92.71 & 64.74 & Reject \\
$\mathrm{M}_{01}$ & 88.10 & 71.66 & Reject \\
$\mathrm{M}_{10}$ & 55.32 & 43.84 & Reject \\
$\mathrm{M}_{11}$ & 41.35 & 49.92 & Accept \\
\hline
\end{tabular}

The estimates of $\beta$ and $\alpha$ from model $M_{11}$ are presented in table $4 \mathrm{a}$. From the $\alpha$ vector we notice that the adjustment coefficient of labor is small and insignificant. Testing that this coefficient is equal to zero is a test that labor is weakly exogenous, which enables the VEC model to be re-specified as a four-equation model conditioning on Labor. Testing that $\mathrm{L}$ is weakly exogenous yields a likelihood ratio test $=0.23$, which compared to the $5 \%$ critical value $\chi^{2}(1)=3.84$, enables us to easily accept the null hypothesis.

The restricted $\beta$ and $\alpha$ are presented in table $4 \mathrm{~b}$. Given the results of this table, we can say that the system is now completely identified. We have estimated a VEC model with one cointegrating vector and L being weakly exogenous. To check the adequacy of the model and make sure that none of the roots have come close to unity, after imposing the weak exogeneity restriction, we checked the eigenvalues of the companion matrix. These eigenvalues, which are not reported here, confirm that the system with restriction has one unit root, with the remaining roots being well inside the unit disc, which confirms once more the choice of $r=1$.

Table 4a: The $\beta$ and $\alpha$ Vectors

\begin{tabular}{|c|c|c|c|c|c|}
\hline RGDP & $\mathrm{PI}$ & GI & $\mathrm{X}$ & $\mathrm{L}$ & Intercept \\
\hline \multicolumn{6}{|c|}{ The $\beta$ vector, normalized on $R G D P$} \\
\hline 1 & $\begin{array}{c}-0.436 \\
(-11.121)\end{array}$ & $\begin{array}{c}-0.182 \\
(-3.420)\end{array}$ & $\begin{array}{c}-0.574 \\
(-7.501)\end{array}$ & $\begin{array}{c}-0.216 \\
(-12.078)\end{array}$ & $\begin{array}{c}-1.346 \\
(-20.802)\end{array}$ \\
\hline \multicolumn{6}{|c|}{ The adjustment coefficients $\alpha$} \\
\hline $\begin{array}{c}-0.621 \\
(-5.334)\end{array}$ & $\begin{array}{c}0.587 \\
(4.972)\end{array}$ & $\begin{array}{c}0.356 \\
(3.622) \\
\end{array}$ & $\begin{array}{c}0.442 \\
(4.791)\end{array}$ & $\begin{array}{c}0.008 \\
(1.026) \\
\end{array}$ & \\
\hline \multicolumn{6}{|c|}{ Table 4b: The Restricted $\beta$ And $\alpha$ Vectors } \\
\hline RGDP & $\mathrm{PI}$ & GI & $\mathrm{X}$ & $\mathrm{L}$ & Intercept \\
\hline \multicolumn{6}{|c|}{ The $\beta$ vector, normalized on $R G D P$} \\
\hline 1 & $\begin{array}{c}-0.438 \\
(-11.135)\end{array}$ & $\begin{array}{c}-0.185 \\
(-3.422)\end{array}$ & $\begin{array}{c}-0.576 \\
(-7.504)\end{array}$ & $\begin{array}{c}-0.214 \\
(-12.069)\end{array}$ & $\begin{array}{c}-1.348 \\
(-20.806)\end{array}$ \\
\hline \multicolumn{6}{|c|}{ The adjustment coefficients $\alpha$} \\
\hline $\begin{array}{c}-0.620 \\
(-5.334) \\
\end{array}$ & $\begin{array}{c}0.589 \\
(4.972) \\
\end{array}$ & $\begin{array}{c}0.355 \\
(3.622) \\
\end{array}$ & $\begin{array}{c}0.445 \\
(4.791) \\
\end{array}$ & & \\
\hline
\end{tabular}


Now we are in a position to give an economic interpretation to the results of cointegration in table $4 \mathrm{~b}$. First, the results of cointegration indicate that real output, exports, labor, and both sorts of investment have a long-run equilibrium relationship. This means that the short-run dynamics of real output, exports, and both investment types can be interpreted as a continuous adjustment towards reaching this equilibrium. Second, from the $\alpha$ vector, we can see how fast the different variables are adjusting to this equilibrium, which also indicates the amount by which the disequilibrium is corrected in each short-term period. In this respect, we can see that real output, private investment, public investment, and exports are all adjusting to the long-run equilibrium but with different speed of adjustment. In particular, output and exports have a relatively high speed of adjustment to the long-run equilibrium state. Third, and most important, since the variables are measured by their natural logarithm, the coefficients of the cointegrating vector can be interpreted as the long-run elasticities of real output with respect to the different variables in the system. With this, we can see that the elasticity of real output with respect to exports is the highest among the variables $(0.576)$, followed by private investment (0.438), labor (0.214), then public investment (0.185). In particular, we can see that private investment has a much higher effect on real output than that of public investment.

\section{Test Results For Granger Noncausality}

The results of cointegration above imply that the variables have a vector error-correction representation of the form:

$$
\begin{aligned}
& \Delta R G D P_{t}=c_{1}+\alpha_{1} v_{t-1}+\sum_{i=1}^{3} \delta_{1, i} \Delta R G D P_{t-i}+\sum_{i=1}^{3} \gamma_{1, i} \Delta P I_{t-i}+\sum_{i=1}^{3} \varphi_{1, i} \Delta G I_{t-i}+\sum_{i=1}^{3} \phi_{1, i} \Delta X_{t-i}+\sum_{i=1}^{3} \psi_{1, i} \Delta L_{t-i}+d_{1} D U M_{t}+e_{1 t} \\
& \Delta P I_{t}=c_{2}+\alpha_{2} v_{t-1}+\sum_{i=1}^{3} \delta_{2, i} \Delta R G D P_{t-i}+\sum_{i=1}^{3} \gamma_{2, i} \Delta P I_{t-i}+\sum_{i=1}^{3} \varphi_{2, i} \Delta G I_{t-i}+\sum_{i=1}^{3} \phi_{2, i} \Delta X_{t-i}+\sum_{i=1}^{3} \psi_{2, i} \Delta L_{t-i}+d_{2} D U M_{t}+e_{2 t} \\
& \Delta G I_{t}=c_{3}+\alpha_{3} v_{t-1}+\sum_{i=1}^{3} \delta_{3, i} \Delta R G D P_{t-i}+\sum_{i=1}^{3} \gamma_{3, i} \Delta P I_{t-i}+\sum_{i=1}^{3} \varphi_{3, i} \Delta G I_{t-i}+\sum_{i=1}^{3} \phi_{3, i} \Delta X_{t-i}+\sum_{i=1}^{3} \psi_{3, i} \Delta L_{t-i}+d_{3} D U M_{t}+e_{3 t} \\
& \Delta X_{t}=c_{4}+\alpha_{4} v_{t-1}+\sum_{i=1}^{3} \delta_{4, i} \Delta R G D P_{t-i}+\sum_{i=1}^{3} \gamma_{4, i} \Delta P I_{t-i}+\sum_{i=1}^{3} \varphi_{4, i} \Delta G I_{t-i}+\sum_{i=1}^{3} \phi_{4, i} \Delta X_{t-i}+\sum_{i=1}^{3}{ }_{4, i} \Delta L_{t-i}+d_{4} D U M_{t}+e_{14}
\end{aligned}
$$

where $v$ is the cointegrating vector in table $4 \mathrm{~b}$ and $D U M$ is a dummy variable accounting for structural change. To test for Granger noncausality we use the LR test in (10) and test whether all lagged coefficients of a variable and the coefficient of the cointegrating vector are jointly equal to zero in an equation. As mentioned earlier, this test can be interpreted as a test for both short- and long-run noncausality. For example, to test whether PI does not Granger-cause output growth in equation (13), we test the null hypothesis:

\begin{tabular}{|c|c|c|c|c|}
\hline Variable & $\Delta$ RGDP & $\Delta \mathrm{PI}$ & $\Delta \mathrm{GI}$ & $\Delta \mathrm{X}$ \\
\hline$\Delta \mathrm{RGDP}$ & -------- & $15.67 *$ & $12.03 * *$ & $17.41^{*}$ \\
\hline$\Delta \mathrm{PI}$ & $20.46^{*}$ & -------- & $13.55^{*}$ & $16.82 *$ \\
\hline$\Delta \mathrm{GI}$ & $10.09 * *$ & 5.93 & -------- & $10.66^{* *}$ \\
\hline$\Delta \mathrm{X}$ & $22.35^{*}$ & $16.27 *$ & $8.37 * * *$ & -------- \\
\hline$\Delta \mathrm{L}$ & $11.84 * *$ & 7.11 & 5.09 & 5.67 \\
\hline
\end{tabular}

$\mathbf{H}_{0}: \gamma_{1,1}=\gamma_{1,2}=\gamma_{1,3}=\alpha=0$

which is distributed $\lambda^{2}(4)$.

Table 5: Test Results For Granger Noncausality

$*, * *, * * *$, indicate significance at the $1 \%, 5 \%$, and $10 \%$ levels, respectively. 
Table 5 reports the results of testing for Granger noncausality between all variables in the system. The flow of causality in this table is from the variables in the first column to the variables in the first row. The main findings from this table can be summarized as follows:

Both sorts of investment, private and public, Granger-cause economic growth. This implies that changes in private investment as well as changes in public investment rates help predict future changes in economic growth in Tunisia. In addition, the flow of causality seems to be running in both directions between growth and private investment and between growth and public investment, which implies that economic growth is in part responsible for future changes in private and public investment rates. As expected, the remaining variables, export growth and labor force growth, do have a causal impact on economic growth, which means that exports and labor force are also growth determining variables in Tunisia. In addition, the flow of causality between exports and economic growth is running in both directions, meaning that economic growth in Tunisia leads to export growth. Thus, the short- and long-run dynamics of economic growth in Tunisia seems to depend on changes in private and public investment rates, export growth, and labor force growth.

(ii) Export growth is being Granger-caused by both types of investment and by economic growth. Thus, changes in private and public investment rates both have an effect on future growth rates of exports. Taken in conjunction with the result that exports promote economic growth, this implies the existence of an indirect causal link between the two types of investment and economic growth. This indirect link is the result of private and public investment causing export growth, which in turn causes economic growth. Thus, added to the results in $(i)$, this result leads us to conclude that the relationship between both sorts of investment and economic growth is based on direct as well as indirect causal links. The indirect causal link is the result of both types of investment causing export growth. It should be noted that, as opposed to single growth equation estimation, this result is the consequence of treating exports as endogenous to the system.

(iii) There is a one-way causal relationship running from private to public investment. While changes in private investment are in part responsible for future changes in public investment, changes in public investment have no causal impact on future private investment rates. This means that changes in public investment in Tunisia are following rather than anticipating changes in private investment. Therefore an increase (decrease) of the share of public investment in GDP does not have an impact on future investment rates in the private sector, whereas, a growing private sector will in due time induce the public sector to provide essential investments in social and economic infrastructure.

\section{Results Of Variance Decompositions}

The results above identify the causal patterns that exist between the variables. They do not, however, allow gauging the strength of these relationships. In order to have indications about the causal relativities, we use variance decompositions and estimate the future responses of economic growth and international trade to a one standard deviation innovation in each variable in the system including their own. We do this by decomposing the forecast variance of economic growth and exports into proportions attributable to each variable within a 10-year horizon. These decompositions are obtained using random generation of the parameters of the VEC model in (13) - (16) in a Monte Carlo experiment with 100 iterations. Since the innovations are not necessarily totally uncorrelated, the residual terms are orthogonalized using a Choleski decomposition in order to obtain a diagonal covariance matrix of the resulting innovations and, therefore, isolate the effects of each variable.

The main results of these decompositions are presented in table 6 . The main conclusions from this table can be summarized as follows:

(i) Economic growth in Tunisia is endogenous in the sense that it allows being explained by the other variables in the model. Export-growth has the highest contribution to economic growth. About $23 \%$ of the forecast variance of growth is explained by exports. Private and public investments explain about $16 \%$ of future growth rates of real GDP. In particular, a one standard deviation innovation to private investment generates a permanent effect on growth that reaches about $13 \%$ of the total forecast variance, while a one standard 
deviation innovation to public investment generates a permanent effect on growth that reaches only $2 \%$. This result implies that private sector investment has a stronger effect on economic growth in the sense that an increase in the share of private investment generates a higher effect on economic growth than a similar increase in the share of public investment.

Table 6: Variance Decompositions

\begin{tabular}{cccccccc}
\hline $\begin{array}{c}\text { Forecast } \\
\text { variance } \\
\text { of }\end{array}$ & $\begin{array}{c}\text { Forecast } \\
\text { error }\end{array}$ & $\begin{array}{c}\text { Forecast } \\
\text { Period } \\
\text { (years) }\end{array}$ & $\Delta$ RGDP & \multicolumn{5}{c}{ Percentage of forecast variance due to innovations in } \\
\hline \multirow{3}{*}{$\Delta$ RGDP } & 0.00485 & 2 & 88.394 & 3.620 & $\Delta$ PI & $\Delta \mathrm{X}$ & $\Delta \mathrm{L}$ \\
& 0.00647 & 4 & 78.008 & 11.046 & 0.417 & 5.908 & 1.661 \\
& 0.00724 & 6 & 71.220 & 11.895 & 1.635 & 8.334 & 1.877 \\
& 0.00765 & 8 & 64.914 & 12.701 & 2.134 & 17.399 & 2.540 \\
& 0.00891 & 10 & 57.333 & 13.559 & 2.240 & 23.200 & 3.668 \\
$\Delta \mathrm{X}$ & & & & & & & \\
& 0.0097 & 4 & 2.007 & 1.523 & 0.752 & 95.651 & 0.067 \\
& 0.0121 & 8 & 3.255 & 2.119 & 0.820 & 93.676 & 0.103 \\
& 0.0146 & 12 & 6.717 & 5.901 & 1.348 & 85.922 & 0.112 \\
& 0.0159 & 16 & 9.356 & 8.761 & 1.376 & 80.351 & 0.156 \\
& 0.0196 & 20 & 10.440 & 10.801 & 1.466 & 77.116 & 0.177 \\
\hline
\end{tabular}

(ii) Export growth is mostly explained by economic growth and private investment. Together, private investment and economic growth explain about $21 \%$ of the total forecast variance of export growth rates. Public investment and labor force growth together explain about $2 \%$ of the future growth rates of exports. In particular, there is a significant difference between the contributions of private and public investment to the future changes in export growth. Private investment has a higher contribution which reaches about $10 \%$, while public investment has a low contribution of about $1.5 \%$ of the total change in export growth rates.

In light of the above results, it is clear that private sector investment in Tunisia has a more significant role than the public counterpart in promoting international trade and economic growth. Consequently, it is safe to conclude that privatization should lead to a better allocation of resources in Tunisia. The government efforts in the ongoing privatization process should, therefore, be directed towards enhancing further the competitiveness of the private sector and its role in the economy. This policy, however, may be necessary but not sufficient for the private sector to take the lead and compete successfully in the global economy. There are at least three additional requirements for this policy to be successful. First, as the results of Granger noncausality suggest, public investment is required to provide in due time the economic infrastructure and social investments needed for an expanding private sector. This requires public authorities in Tunisia to reorient public capital spending from inefficient productive activities into providing public goods, such as infrastructure and social services, needed by the private sector. Second, as suggested by Ghali (1999), the government is required to develop financial markets in order to mobilize resources for the private sector. Finally, while the analysis abstracts from including any institutional aspects, we are aware of the fact that the process of economic development is a complex cumulative process of institutional change. In this respect, we believe that, for privatization to be successful, it should take into account the role of institutions in providing a favorable environment that promotes the activities of the private sector.

\section{CONCLUSION}

This paper attempted to empirically investigate the separate effects of private and public capital on international trade and economic growth in Tunisia. The objective is to provide evidence on whether an alteration of the ownership structure of capital in favor of privatization would ameliorate resource allocation and, subsequently, promote international trade and economic growth. For Tunisia, this is an important issue to investigate as the country is rapidly moving from a centrally planned economy into an open, market oriented one, with no existing evidence on the distinctive effects of private and public capital on trade development and growth. In addition, opponents to 
privatization are raising doubts about the ability of the private sector to take the lead and compete successfully in the global economy.

Based on a modified version of the neo-classical one-sector aggregate production technology, the separate effects of private and public capital were analyzed in a five variable system consisting of real GDP, private investment, public investment, exports and labor. In an attempt to improve upon the existing empirical growth models that are based on a single equation, we developed a vector error-correction model in which all variables are endogenous, hence, allowing by that to distinguish between the effects of investment on growth and trade based on the ownership structure of capital. Using this model we were able to: $(i)$ test for the existence of a long-run equilibrium relationship between the variables and, particularly, estimate the separate long-run effects (elasticities) of private and public investment on economic growth, (ii) identify the causal flows between the variables in the system and, particularly, the channels through which private and public investment interact with each other and affect international trade and growth, and (iii) estimate the separate contribution of private and public investment to the future growth rates of trade and real output through variance decompositions.

The main findings from the empirical analysis suggest that private and public investment cointegrate with real output, exports and labor, with private investment having a much higher effect on output than public investment in the long-run. The Granger noncausality tests revealed that private and public investment, both, have a causal impact on exports and growth. However, upon decomposing the forecast variance of trade and growth, we found that private investment has a much higher contribution to future trade and growth performance. These findings led to the conclusion that an alteration of the ownership structure of capital in favor of the private sector should lead to better allocation of resources. However, for this process to be successful, it is recommended that the government respond, in due time, to the needs of the private sector in terms of providing the necessary infrastructure, developing financial markets, and ameliorating the institutional framework.

\section{REFERENCES}

1. Barro, R.J. (1981) Output Effects of Government Purchases, Journal of Political Economy, 89:6, 1086-1121.

2. Barro, R. J. (1990) Government Spending in a Simple Model of Endogenous Growth, Journal of Political Economy, part 2, 98, 103-25.

3. Barro, R. J., (1991) Economic Growth in a Cross Section of Countries, Quarterly Journal of Economics, 106, 407-44.

4. Barro, R.J. and Sala-i-Martin, X. (1992) Convergence, Journal of Political Economy, 100, 223-51.

5. $\quad$ Bennedsen, M. (1998) Political Ownership, Mimeo, 1998.

6. Boycko, M. A. Shleifer, and R.W. Vishny (1995) Privatizing Russia, Cambridge, MA: MIT Press.

7. Caporale, G.M. and N. Pittis (1999) Efficient estimation of Cointegrating Vectors and Testing for Causality in Vector Autoregressions, Journal of Economic Surveys, 13, 1-35.

8. $\quad$ Christiano, L.J. (1992) Searching for a Break in GNP, Journal of Business and Economic Statistics 10, 237250.

9. Dollar, D. (1992) Outward-Oriented Developing Economies Really Do Grow More Rapidly: Evidence from 95 LDCs, 1976-1985, Economic Development and Cultural Change, 40, 523-44.

10. Dolado, J.J. and H. Lutkepohl (1996) Making Wald Tests Work for Cointegrated VAR Systems, Econometric Reviews, 15, 369-386.

11. Easterly, W.R. (1992) Endogenous Growth in Developing Countries With Government-induced Distortions, in Adjustment Lending Revisited: Policies to Restore Growth, edited by Vittorio Corbo and Stanley Fisher. Washington, D.C.

12. Edwards, S. (1989) Openness, Outward Orientation, Trade Liberalization and Economic Performance in Developing Countries, World Bank Working Paper Series No. 191.

13. Feder, G. (1983) On Exports and Economic Growth, Journal of Development Economics, 12, 59-74.

14. Ghali, K.H. (1999) Government Size and Economic Growth: A Multivariate Cointegration Analysis, Applied Economics, 31, 975-987.

15. Giles, J.A. and S. Mirza (1999) Some Pretesting issues on Testing for Granger Noncausality, Working Paper EWP9914, University of Victoria. 
16. Grossman, G. M. and Helpman, E. (1990) Trade, Innovation, and Growth, American Economic Review (Papers and Proceedings), 80, 86-91.

17. Hsieh, E. and Lai, K. (1994) Government Spending and Economic Growth, Applied Economics, 26, 535-542.

18. Johansen, S. (1988) Statistical Analysis of Cointegration Vectors, Journal of Economic Dynamics and Control 12, 231-254.

19. Johansen, S. (1992b) Determination of the Cointegration Rank in the Presence of a Linear Trend, Oxford Bulletin of Economics and Statistics, 54, 383-397.

20. Johansen, S. (1994) The Role of the Constant and Linear Terms in Cointegration Analysis of Nonstationary Variables, Econometric Reviews 13, 205-229.

21. Kormendi, R. and Meguire, P. (1985) Macroeconomic Determinants of Growth: Cross-Country Evidence, Journal of Monetary Economics, 16, 141-63.

22. Landau, D. (1983) Government Expenditure and Economic Growth: A Cross-Country Study, Southern Economic Journal, 49, 783-92.

23. Levine, R. and D. Renelt (1992) A sensitivity Analysis of Cross-Country Growth Regressions, The American Economic Review, 82, 943-963.

24. Nourzad, F. (2000) The Productivity Effect of Government Capital in Developing and Industrialized Countries, Applied Economics, 32, 1181-1187.

25. Pantula, S.G. (1989) Testing for Unit Roots in Time Series Data, Econometric Theory 5, 256-271.

26. Perron, P. (1989) The Great Crash, the Oil-price Shock and the Unit Root Hypothesis, Econometrica, 57, 1361-1401.

27. Perron, P. (1997) Further Evidence on Breaking Trend Functions in Macroeconomic Variables, Journal of Econometrics 80, 355-385.

28. Perron, P. and Vogelsang, T. J. (1992) Nonstationarity and Level Shifts with an Application to Purchasing Power Parity, Journal of Business and Economic Statistics 10, 301-320.

29. Ram, R. (1986) Government Size and Economic Growth: A New Framework and Some Evidence from cross-section and Time Series Data, American Economic Review, 76, 191-203.

30. Ramirez, M.D. (1991) The Impact of Public Investment on Private Capital Formation: A Study Related to Mexico, Eastern Economic Journal, 4, 425-437.

31. Ramirez, M.D. (1994) Public and Private Investment in Mexico, 1950-90: An Empirical Analysis, Southern Economic Journal, 61:1, 1-17.

32. Ramirez, M.D. (1986b) The Composition of Government Spending as an Additional Policy Instrument, Journal of Economics and Business, 38, 215-225.

33. Sen, A. (2003) On Unit Root Tests when the Alternative is a Trend-break Stationary Process, Journal of Business and economic Statistics 21:1, 174-184.

34. Shleifer, A. (1998) State versus Private Ownership, Journal of Economic Perspectives, 12, 133-150.

35. Toda, H. (1995) Finite sample performance of likelihood ratio tests for cointegration ranks in vector autoregressions, Econometric Theory 11, 1015-1032.

36. Toda, H. and P.C.B. Phillips (1993) Vector autoregressions and causality, Econometrica 61, 1367-1393.

37. Toda, H. and P.C.B. Phillips (1994) vector autoregression and causality: A theoretical overview and simulation study, Econometric reviews 13, 259-285.

38. Vogelsang, T.J. and Perron, P. (1998) Additional Tests for a Unit Root Allowing for a Break in the Trend Function at an Unknown Time, International Economic Review 39, 1037-1100.

39. Yamada, H. and H.Y. Toda (1998) Inference in Possibly Integrated Vector Autoregressive Models: Some Finite Sample Evidence, Journal of Econometrics, 86, 55-95.

40. Zapata, H.O. and A.N. Rambaldi (1997) Monte Carlo Evidence on Cointegration and Causation. Oxford Bulletin of Economics and Statistics, 59, 285-298.

41. Zivot, E. and Andrews D.W.K. (1992) Further Evidence on the Great Crash, the Oil Price Shock, and the Unit Root Hypothesis, Journal of Business and Economic Statistics 10, 251-270. 